\title{
PENGARUH PARTISIPASI MASYARAKAT DAN KEBIJAKAN PEMERINTAH TERHADAP KESEJAHTERAAN MASYARAKAT MELALUI KEBERLANJUTAN PARIWISATA NUSA PENIDA
}

\author{
Ni Kadek Ayu Indrayani ${ }^{1}$ \\ Nyoman Djinar Setiawina ${ }^{2}$
}

${ }^{1}$ Fakultas Ekonomi dan Bisnis Universitas Udayana (Unud), Bali, Indonesia

${ }^{2}$ Fakultas Ekonomi dan Bisnis Universitas Udayana (Unud), Bali, Indonesia email: Ayuina92@gmail.com

\begin{abstract}
ABSTRAK
Pemerintah merancang berbagai program pembangunandengan cara memperbaiki struktur ekonomi daerah.Pariwisata Pulau Nusa Penida merupakan industri yang sedang dikembangkan oleh Pemerintah Kabupaten Klungkunguntuk meningkatkan kualitas hidup masyarakat. Tujuan penelitian ini adalah menganalisis. 1) Bagaimana pengaruh partisipasi masyarakat dan peran pemerintah terhadap keberlanjutan pariwisata Nusa Penida; 2) Bagaimana pengaruh keberlanjutan pariwisata Nusa Penida terhadap kesejahteraan masyarakat; dan 3) Apakah variabel partisipasi masyarakat dan peran pemerintah berpengaruh secara tidak langsung terhadap kesejahteraan masyarakat melalui keberlanjutan pariwisata Nusa Penida. Sumber data yaitu data primer yang diperoleh dari kuisioner, dengan jumlah responden sebanyak 98 orang. Alat analisis yang digunakan adalah SEM-PLS.

Kata Kunci: Partisipasi, Kebijakan Pemerintah, Keberlanjutan Pariwisata, Kesejahteran.
\end{abstract}

\begin{abstract}
ABSTACT
The Government designed various development programs by improving the regional economic structure. Tourism Nusa Penida Island is an industry that is being developed by the Government of Klungkung Regency to improve the quality of life of the community. Based on that data this study is aimed to analyze:1) how are the influences of society participation and the role of government to the sustainable tourism in Nusa Penida; 2) how is the influence of sustainable tourism to the prosperty of society; and 3) do variable of society participation and the role of the government indirectly influence the prosperty of society through the sustainable tourism in Nusa Penida. Sources of data are primary data obtained from the questionnaire, with the number of respondents as many as 98 people. The analysis tool used is SEM-PLS.

Key words : Participation, Government Policy, Sustainable Tourism, Prosperity.
\end{abstract}


Ni Kadek Ayu Indrayani, dan N. Djinar Setiawina. Pengaruh Partisipasi Masyarakat..........

\section{PENDAHULUAN}

Masyarakat yang sejahtera adalah salah satu pencapaian keberhasilan pembangunan. Kesejahteraan secara umum tidak hanya merujuk pada tingkat kesejahteraan secara ekonomi semata, tetapi juga melibatkan seluruh aspek kehidupan atau lingkungan sosialnya(Albert dan Hannel, 1999). Pada dasarnya untuk mencapai kesejahteraan masyarakat dapat dilakukan dengan melaksanakan perubahan-perubahan kehidupan yang lebih baik melalui pembangunan. Sumberdaya manusia (SDM) yang berkualitas menentukantingkat keberhasilan pembangunan. Kualitas sumber daya yang rendah akan menghambat kemampuan seseorang dalam membangun komunikasi, sehingga menjadi hambatan dalam mendukung pembangunan (Arun dan Clark, 1999).

Kualitas SDM sangat perlu mendapat pehatian serius, karena merupakan salah satu faktor penyebab terjadinya penduduk miskin. Rendahnya kualitas SDMakan mengakibatkanmenurunnya produktivitas kerja. Selanjutnya, produktivitas kerja akan mempengaruhi perolehan pendapatan. Pendapatan rendah merupakan penyebab tingginya jumlah penduduk miskin.

Tabel 1.

Persentase Penduduk Miskin Per Kabupaten Provinsi Bali

\begin{tabular}{lllllll}
\hline Kabupaten/Kota & 2011 & 2012 & 2013 & 2014 & 2015 & 2016 \\
\hline Jembrana & 6.56 & 5.74 & 5.56 & 5.83 & 5.84 & 5.33 \\
Tabanan & 5.62 & 4.9 & 5.21 & 5.61 & 5.52 & 5.00 \\
Badung & 2.62 & 2.16 & 2.45 & 2.54 & 2.33 & 2.06 \\
Ginyar & 5.4 & 4.69 & 4.27 & 4.57 & 4.61 & 4.44 \\
Klungkung & 6.1 & 5.37 & 7.01 & 7.01 & 6.91 & 6.35 \\
Bangli & 5.16 & 4.52 & 5.45 & 5.86 & 5.73 & 5.22 \\
Karangasem & 6.43 & 5.63 & 6.88 & 7.30 & 7.44 & 6.61 \\
Buleleng & 5.93 & 5.19 & 6.31 & 6.79 & 6.74 & 5.79 \\
Denpasar & 1.79 & 1.52 & 2.07 & 2.21 & 2.39 & 2.15 \\
BALI & 4.59 & 3.95 & 4.49 & 4.76 & 4.74 & 4.25 \\
\hline
\end{tabular}

Sumber: BPS Provinsi Bali 2017 
Kabupaten yang memiliki presentase penduduk miskin terbanyak dan cenderung meningkat adalah Kabupaten Karangasem dan Kabupaten Klungkung, bahkan pada tahun 2013 Kabupaten Klungkung merupakan kabupaten yang memiliki presentase jumlah penduduk miskin tertinggi di Provinsi Bali.

Tabel 2.

Persentase Penduduk Miskin Kabupaten Klungkung.

\begin{tabular}{lccc}
\hline Kecamatan & $\begin{array}{c}\text { Jumlah Penduduk } \\
(\mathrm{KK})\end{array}$ & $\begin{array}{c}\text { Jumlah Penduduk Miskin } \\
(\mathrm{KK})\end{array}$ & $\begin{array}{c}\text { Presentase } \\
(\%)\end{array}$ \\
\hline Klungkung & 16.997 & 2.238 & 13.57 \\
Banjarangkan & 12.620 & 1.615 & 13.08 \\
Dawan & 11.173 & 1.637 & 14.67 \\
Nusa Penida & 16.576 & 5.668 & 34.19 \\
\hline Sumber: Klungkung Dalam Angka 2016 & &
\end{tabular}

Kabupaten Klungkung terdiri dari empat kecamatan, yaitu Kecamatan Klungkung, Banjarangkan, Dawan, dan Nusa Penida.Nusa Penida merupakan kecamatan penyumbang jumlah penduduk miskin terbesar di Kabupaten Klungkung. Hal tersebut diakibatkan oleh kondisi geografis Kecamatan Nusa Penida yang kering dan tandus, sehingga tanaman pangan tidak dapat tumbuh dengan baik. Kondisi tersebut diperparah mengingat aksessibilitas yang terbatas karena Pulau Nusa Penida dipisahkan oleh perairan/laut. (Purbadharmaja, dkk, 2014).

Pemerintah daerah melakukan berbagai terobosan baru guna meningkatkan pertumbuhan daerah yang selanjutnya akan berdampak terhadap perbaikankondisi ekonomi dan sosial masyarakat. Kebijakan pemerintah yang dilakukan saat ini yang adalah memperbaiki struktur perekonomian dan mengembangkan sektor andalan, serta mengoptimalkan potensi daerah. 
Ni Kadek Ayu Indrayani, dan N. Djinar Setiawina. Pengaruh Partisipasi Masyarakat..........

Industri pariwisata Kabupaten Klungkung yang diwakili oleh penyediaan akomodasi dan makan minum selama tahun 2011-2016 sumbangannya mengalami kecenderungan meningkat. Hal sebaliknya terjadi pada industri pertanian yang justru mengalami kecenderungan menurun, meskipun sedikit naik pada tahun 2015 tetapi tidak mampu bertahan pada tahun 2016. Kecenderungan menurunnya share lapangan usaha pertanian antara lain disebabkan adanya alih fungsi lahan pertanian (lahan sawah) menjadi lahan non pertanian (pemukiman).

Gambar 1.

Kontribusi PDRB Lapangan Usaha Pertanian dan Lapangan Usaha Penyedia Akomodasi dan Makan Minum Terhadap PDRB Kabupaten Klungkung Tahun 2011-2016 (Persen).

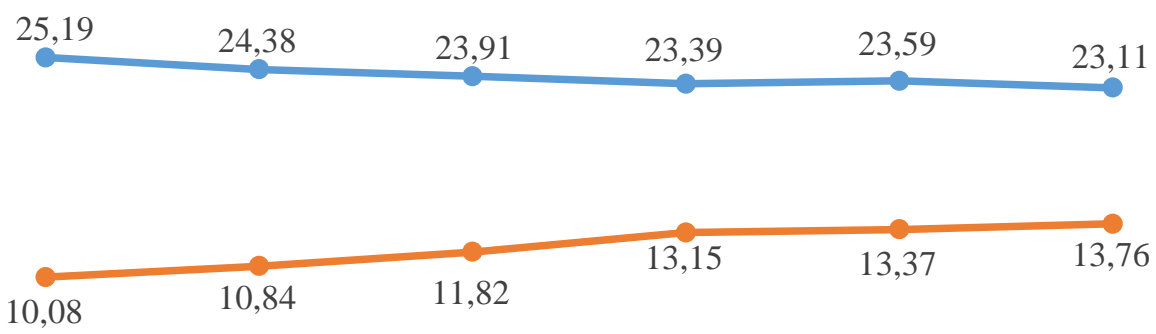

-Pertanian, Kehutanan dan Perikanan
- Penyediaan Akomodasi dan Makan Minum

Sumber: BPS Kabupaten Klungkung, 2017

Kategori penyediaan akomodasi dan makan minum memberikan share cukup besar terhadap PDRB Kabupaten Klungkung. Kategori ini memiliki kecenderungan meningkat dari tahun ke tahun hinggamencapai13,76 persen di tahun 2016. Kondisi tersebut selaras dengan jumlah kunjungan wisatawan yang terus meningkat ke Kabupaten Klungkung terutama ke wilayah Nusa Penida. 
Tabel 3.

Kunjungan Wisatawan Asing dan Domestik Objek Wisata Kabupaten Klungkung.

\begin{tabular}{llllll} 
Objek Wisata & 2011 & 2012 & 2013 & 2014 & 2015 \\
\hline Kertha Gosa & 54.684 & 60.262 & 54.745 & 45.795 & 43.683 \\
Goa Lawah & 52.309 & 53.472 & 55.308 & 58.918 & 57.550 \\
Kawasan Nusa Penida & 132.095 & 127.836 & 185.909 & 22.0751 & 264.708 \\
Levi Rafting & 3.524 & 3.629 & 3.017 & 2.849 & 6.110 \\
\hline
\end{tabular}

Sumber: Klungkung Dalam Angka 2016

Saat ini kawasan Pulau Nusa Penida mulai menjadi salah satu kawasan destinasi wisata yang diminati wisatawan di Bali. Objek wisata harus memiliki atraksi, aksesibilitas, dan fasilitas yang mendukung keberhasilan suatu tempat wisata (Yunia dan Petrus, 2015). Pulau Nusa Penida memiliki beberapa kawasan wisata selam sehingga atraksi pariwisata bahari seperti diving, snorkling, surfing, parasailing, menjadi keunggulan tersendiri dibandingkan daerah lainnya(Donny, 2015).Kawasan Nusa Penida memiliki beraneka ragam hayati laut sepertisegitiga terumbu karang dunia(the coral triangle), hutan bakau, ikan pari manta, ikan mola mola, penyu, lumba-lumba, hiu dan paus. Nusa Penida juga ditetapkan sebagai Kawasan Konservasi Perairan (KKP) Taman Wisata Perairan Nusa Penida, pada saat Festival Nusa Penida tanggal 9 Juni tahun 2014 (Werdika, dkk, 2015).

Akses menuju Pulau Nusa Penida melalui pelabuhan Benoa, Sanur, Padangbai dan pelabuhan Kusambadengan menggunakankapal wisata, speed boat dan perahu tradisional (jukung). Sedangkan di kawasan barat Pulau Nusa Penida terdapat pelabuhan Toyapakeh dan pelabuhan Banjar Nyuh, pelabuhan Buyuk dan pelabuhan Mentigi.Di kawasan Nusa Penida juga sudah tersedia villa, homestay, restaurant, bar, café, Tourist Information Centre, artshop untuk wisatawan. 
Ni Kadek Ayu Indrayani, dan N. Djinar Setiawina. Pengaruh Partisipasi Masyarakat..........

Permasalahan yang terjadi saat ini adalah dengan banyaknya potensi wisata yang dimiliki justru Nusa Penida dipandang belum mampu sebagai daerah distinasi pariwisata yang memiliki konsep berkelanjutan. Trend perkembangan pariwisata saat ini lebih berorientasi ke ekonomi, dimana lebih memikirkan keuntungan ekonomi dibandingkan pelestarian lingkungan.

Permasalahan lain yang saat ini juga dihadapai oleh Nusa Penida adalah kawasan barat Pulau Nusa Penida merupakan kawasan yang memiliki potensi daya tarik wisata yang beraneka ragam. Enam desa yang ada di wilayah barat Pulau Nusa Penida seperti; Desa Ped, Bunga Mekar, Sakti, Toyapakeh, Batukandik dan Batumadeg kepariwisatanya belum berkembang dan belum ditetapkan sebagai Daya Tarik Wisata (DTW) di Kabupaten Klungkung, padahal pembangunan daerah seharusnya merata apalagi sebagian besar desa yang berada di kawasan barat Pulau Nusa Penida memeliki potensi daya tarik wisata yang beraneka ragam dan layak untuk dikembangkan (Darsana, 2011).

Keberlanjutan pembangunan pariwisata di Nusa Penida diharapkan dapat menjaga sumber daya alam dan budaya serta dapat memberikan manfaat ekonomi. (Michael Fagence, 2001).Indikator yang sering dijadikan gambaran karakteristik pariwisata berkelanjutan antara lain adalah lingkungan, sosial dan budaya, serta aspek ekonomi. World Tourism and Travel Council (WTTC) bekerja sama dengan World Tourism Organization dan Earth Council juga menyimpulkan konsep pariwisata yang dicita-citakan masyarakat harus menekankan aspekekologi, ekonomi, dan sosial budaya untuk keberlanjutan pengembangan kawasan 
pariwisata, serta perencanaan dan pelanksaan dari semua stakeholder (Suardana, 2011).

Dalam rangka menjawab tantangan tersebut, maka diperlukan partisipasi aktif masyarakatdibarengi dengan sistem penyelenggaraan kepemerintahan yang baik sehingga tujuan pembangunan pariwisata berkelanjutan akan dapat tercapai(Joko, 2014).

Pemerintah adalah aktor utama dalam proses politik pembangunan pariwisata. Pemerintah mengontrol industri melalui kementerian, lembagalembaga lain, peraturan perundang-undangan, dan inisiatif pendanaan (James, 1997).Pemerintah sekarang biasanya mencoba untuk menyeimbangkan antara prioritas ekonomi, lingkungan, dan warga setempat untuk mendapatkan dukungan politik dengan tujuan pengembangan pariwisata (Bill, 2011). Pemerintahan juga harus memastikan bahwa warga setempat mendukung kebijakan agar tujuan pembangunan tercapai (Yi dan Bill, 2012).

Menurut Hall dalam Aleksandra dan Tamara (2014) dalam pengembangan pariwisata, pemerintah memiliki tujuh peranyaitu koordinasi, perencanaan, undang-undang dan peraturan, kewirausahaan, stimulasi, pariwisata sosial, dan peran perlindungan kepentingan umum. Stimulasi disinidapat dilakukan secara financial seperti memberikan pinjaman dengan bunga rendah (Theobald, 2005). Sedangkan keterlibatan sektor publik dalam pariwisatamenurut Mill and Morrison dalam Hall (2000) yaitu koordinasi, perencanaan, perundang-undangan dan peraturan, kewirausahaan dan stimulasi.Dalam rangka pengembangan destinasi wisata di sebuah kawasan tertentu, pemerintah lokal lebih banyak berperan dalam 
Ni Kadek Ayu Indrayani, dan N. Djinar Setiawina. Pengaruh Partisipasi Masyarakat..........

menyediakan antara lain, (1) pendanaan, (2) menyediakan fasilitas atraksi, seperti pembangunan museum, galeri, taman rekreasi, serta (3) penyediaan infrastruktur dan seterusnya (Joanne et al, 2009)

Masyarakat juga memegang peranan penting dalam pengembangan pariwisata Nusa Penida.Partisipasi diartikan sebagai proses aktif, inisiatif diambil oleh seseorang dimana mereka mampumemberikan kontrol secara efektif (Cohen dan Uphoff dalam Isma dan Fredian, 2011). Partisipasi masyarakat yang sering diabaikan merupakan awal kegagalan pengembangan pariwisata (Nasikun, 1997).Potensi daya tarik wisata seringkali tidak berhasil diwujudkan menjadi destinasi wisata, disebabkan karena terjadinya perebutan sumber daya alam yang pada akhirnya membawa konflik antar masyarakat dengan pengelola destinasi wisata (Jamal dan Stronza, 2009).

Kajian destinasi wisata ditentukan oleh keberadaan partisipasi masyarakat menjadi bagian yang tidak terpisahkan dengan pembangunan destinasi wisata (Tosun, 2006). Masyarakat menjadi komponen penentu dalam pengembangan daerah wisata(Aref et al,2010) . Peran masyarakat dapat menentukan keberhasilan pengembangan pariwisata, dimana keterlibatan masyarakat akan menyebabkan dukungan terhadap pariwisata oleh masyarakat sehingga pariwisata akan terus berkembang (Ma'rifatul Kholifah,2015). Keterlibatan masyarakat dalam pembangunan dapat dmulai dari tahap perencanaan, pelaksanaan, pengawasan, dan pelestarian (Timothy,1999). Godfrey dan Clarke dalam Michael et al (2013) menyimpulkan bahwa komunitas lokal merupakan komponen strategis yang berfungsi melaksanakan (1) pelayanan, (2) penyedia akomodasi, (3) penyedia 
transportasi, (4) pelestarian lingkungan alam, dan (5) memberikan dukungan budaya. Selain itu, masyarakat juga dapat mengambil peran sebagai agen promosi untuk membangun interaksi dan partisipasi dalam pengambilan keputusan(Isye, dkk, 2017)

\section{METODE PENELITIAN}

Penelitian ini dilaksanakan di enam desa yang ada di wilayah Pulau Nusa Penida seperti; Desa Ped, Bunga Mekar, Sakti, Toyapakeh, Batukandik dan Desa Batumadeg yang kepariwisatanya belum berkembang dan belum ditetapkan sebagai Daya Tarik Wisata (DTW) di Kabupaten Klungkung, padahal sebagain besar desa yang berada di kawasan barat Pulau Nusa Penida memeliki potensi daya tarik wisata yang beraneka ragam dan layak untuk dikembangkan.

\section{Jenis Data}

Jenis data yang digunakan pada penelitian ini adalah data primer yaitu langsung didapat dari responden,dalam hal ini masyarakat di Desa Ped, Bunga Mekar, Sakti, Toyapakeh, Batukandik dan Batumadegyang dijadikan sampel dalam penelitian dengan menggunakan kuisioner. Sedangkan data sekunder seperti jumlah penduduk dan gambaran umum daerah penelitian didapatkan dari instansi/lembaga.

\section{Variabel Penelitian}

Variabel dalam penelitian ini ada 4, keberlanjutan pariwisata (Y1), dan kesejahteraan masyarakat (Y2) sebagai variabel dependen, sedangkan partisipasi masyarakat (X1) dankebijakan pemerintah (X2) sebagai variabel independen. 
Ni Kadek Ayu Indrayani, dan N. Djinar Setiawina. Pengaruh Partisipasi Masyarakat..........

\section{Populasi dan Sampel}

Populasi dalam penelitian merupakan jumlah masyarakat di enam desa yaitu Desa Ped, Bunga Mekar, Sakti, Toyapakeh, Batukandik dan Desa Batumadeg sebanyak 5004 orang. Pengambilan sampel dengan teknik Random Sampling dengan jumlah sampel sebanyak 98 responden berdasarkan rumus Slovin.

\section{Definisi Identifikasi Variabel}

1) Variabel Partisipasi Masyarakat (X1) dibentuk oleh 3 indikator dengan 3 butir pertanyaan yang diukur dengan skala ranting 1-5. Rincian masingmasing indikator Partisipasi Masyarakat (X1) yakni, indikator Perencanaan (X1.1), Pelaksanaan (X1.2) dan indikator Pengawasan (X1.3)

2) Variabel Kebijakan Pemerintah (X2) dibentuk oleh 4 indikator dengan 4 butir pertanyaan yang diukur dengan skala ranting 1-5. Indikator variabel Kebijakan Pemerintah (X2) yakni, indikator Stimulasi Kepariwisataan (X2.1), Pembinaan (X2.2), Pembangunan Infrastruktur (X2.3) dan Regulasi Kepariwisataan (X2.4).

3) Variabel Keberlanjutan Pariwisata (Y1) dibentuk oleh 3 indikator dengan 3 butir. Indikator Keberlanjutan Pariwisata (Y1) yakni, Aspek Lingkungan (Y1.1), Aspek Sosial Budaya (Y1.2), dan Aspek Ekonomi (X1.3).

4) Variabel Kesejahteraan Masyarakat (Y2) dibentuk oleh 5 indikator dengan 5 butir pertanyaan yang diukur dengan skala ranting 1-5. Indikator Kesejahteraan Masyarakat (Y2) yakni, indikator Pendapatan (Y2.1), 
Kesehatan (Y2.2), Pendidikan (Y2.3), Kebutuhan Sosial (Y2.4) dan Tabungan (Y2.5).

\section{Teknik Analisis Data}

Penelitian ini melakukan uji instrumen untuk menetapkan apakah instrumen penelitian telah dapat dipahami dengan benar oleh responden dengan uji reliabilitas dan uji validitas. Peneliti dapat mempergunakan software SPSS untuk melakukan uji reabilitas cronbach Alpha dan mempergunakan konsep pengujian validitas dengan memanfaatkan analisis factor dari Kaiser-Meyer-Olkin (KMO) sebagaimana direkomendasikan oleh Tabachnick and Field dalam Sudjana Budhi (2016). Berdasarkan analisis KMO, peneliti dapat memnperolah kelayakan validitas. Jika hasil analisis mendapatkan nilai KMO paling sedikit atau lebih dari 0.70, maka dinyatakan sebaran data categorical bersumber dari multivariate normal distribution. Sedangkan sebaran data categorical dinyatakan reliabel apabila didapatkan paling rendah cronbach Alpha memiliki nilai sebesar 0.60 dapat dinyatakan bahwa data categorical memiliki sebaran data yang reliabel (Hair et al, 2010). Penelitian ini menggunakan teknik analisis model SEM (Structural Equation Model) dengan software Smart PLS (Partial Least Square) yang biasanya digunakan untuk menguji bentuk model sebab akibat (Hair et al, 2010). Analisis PLS SEM dibagi menjadi 2 tahapan yakni, model pengukuran (outer model) dan (2) model struktural (inner model)

1) Evaluasi model pengukuran (outler model)

Untuk menilai aliditas dan reliabilitas model menggunakan evaluasi model pengukuran. Model pengukuranyang bersifat reflektif dapat diuji melalui uji 
Ni Kadek Ayu Indrayani, dan N. Djinar Setiawina. Pengaruh Partisipasi Masyarakat..........

convergent validity, discriminat validity, composite reliability dan cronbach alpha(Chin dalam Ghozali, 2011). Apabila diperoleh hasil uji signifikan, maka indikator dapat digunakan sebagai alat pengukur variabel laten.

1) Evaluasi model struktural (Inner model)

Nilai koefisien determinasi $\left(\mathrm{R}^{2}\right)$ digunakan untukmelihatpengaruh variabel laten eksogen tertentu terhadap variabel laten endogen(Chin dalam Ghozali, 2011). Selanjutnya dengan metode bootstrap untuk melihat pengaruh antar variabel.

\section{HASIL DAN PEMBAHASAN}

\section{Hasil Uji PLS Outer Model}

Hasil uji PLS dengan menggunakan tingkat signifikansi $5 \%$ diperoleh hasil sebagi berikut:

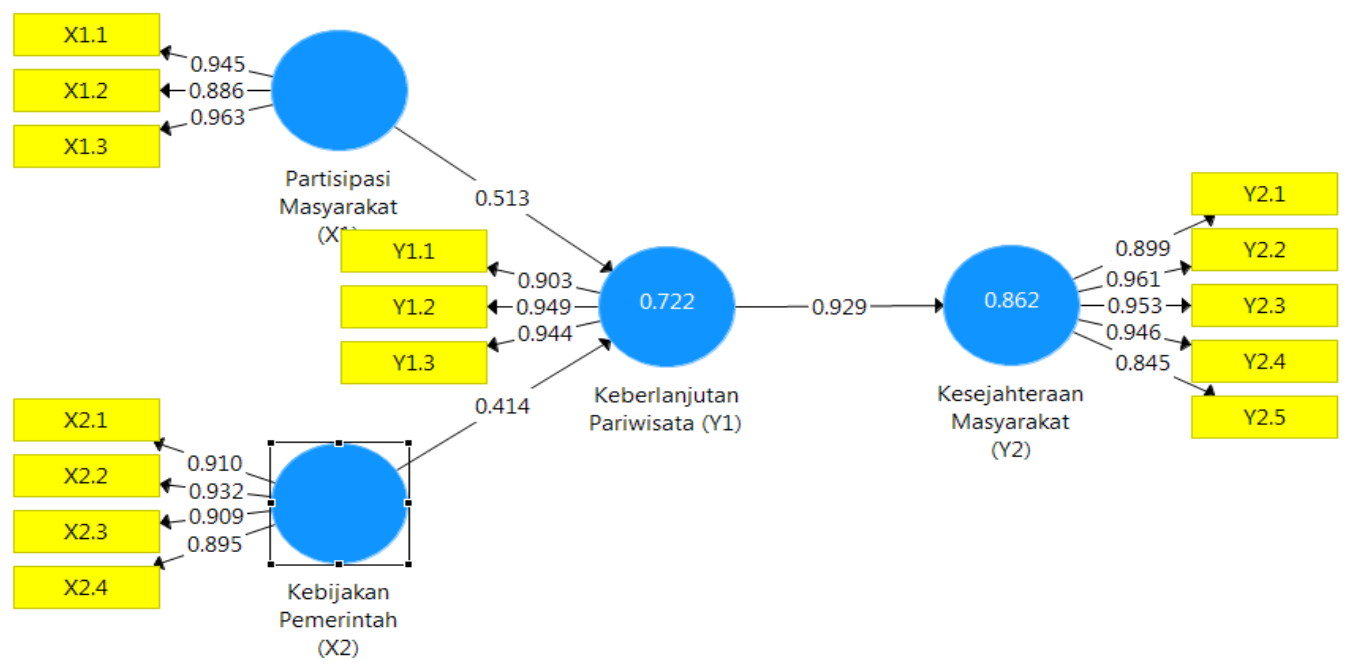

Gambar 2.

Model Jalur Persamaan Struktural 
1) Uji convergent validity

Nilai loading faktor masing-masing indikator dari uji convergent validity, dapat dilihat pada Tabel 4.

Tabel 4.

Hasil uji convergent validity

\begin{tabular}{ccccc}
\hline Indikator & X1 & X2 & Y1 & Y2 \\
\hline X1.1 & 0.945 & & & \\
X1.2 & 0.886 & & & \\
X1.3 & 0.963 & & & \\
X2.1 & & 0.910 & & \\
X2.2 & & 0.932 & & \\
X2.3 & & 0.909 & & \\
X2.4 & & 0.895 & & \\
Y1.1 & & 0.903 & \\
Y1.2 & & 0.949 & \\
Y1.3 & & & 0.994 & \\
Y2.1 & & & 0.899 \\
Y2.2 & & & 0.961 \\
Y2.3 & & & 0.953 \\
Y2.4 & & & 0.946 \\
Y2.5 & & & \\
\hline Sumber: Data diolah, 2017 & & & \\
\hline
\end{tabular}

Sumber: Data diolah, 2017

Uji convergent validity dapat menjelaskan korelasi antar konstruk dengan indikatornya. Korelasi konstruk dalam model ini dinyatakan valid karena nilai loading $>0,70$.

2) Uji Composite Reliability

Composite reliability menjelaskan tentang konsistensi peryataan pada instrumen. Hasil composite reliability menunjukkan nilai Partisipasi Masyarakat sebesar 0,952>0,70, Kebijakan Pemerintah sebesar 0,966>0,70, Keberlanjutan Pariwisata sebesar 0,952>0,70, dan Kesejahteraan Masyarakat sebesar $0,952>0,70$, yang artinya semua variabel dalam model adalah reliabel. 
Tabel 5.

Hasil uji composite reliability

\begin{tabular}{lcc}
\hline \multicolumn{1}{c}{ Variabel } & $\begin{array}{c}\text { Composite } \\
\text { Reliability }\end{array}$ & Keterangan \\
\hline Partisipasi Masyarakat (X1) & 0,952 & Reliabel \\
Kebijakan Pemerintah (X2) & 0,966 & Reliabel \\
Keberlanjutan Pariwisata (Y1) & 0,952 & Reliabel \\
Kesejahteraan Masyarakat (Y2) & 0,952 & Reliabel \\
\hline
\end{tabular}

Sumber: Data diolah, 2017

3) Uji Cronbachs Alpha

Cronbachs alpha menjelaskan konsistensi pernyataan dalam instrumen.

Seluruh variabel dinyatakan reliabel dalam model ini, yaitu memiliki nilai loading>0,7. Nilai cronbachs alpha dapat dilihat pada Tabel 6.

Tabel 6.

Hasil uji Cronbach's Alpha

\begin{tabular}{lcc}
\hline \multicolumn{1}{c}{ Variabel } & Cronbach's Alpha & Keterangan \\
\hline Partisipasi Masyarakat (X1) & 0,924 & Reliabel \\
Kebijakan Pemerintah (X2) & 0,955 & Reliabel \\
Keberlanjutan Pariwisata (Y1) & 0,932 & Reliabel \\
Kesejahteraan Masyarakat (Y2) & 0,925 & Reliabel
\end{tabular}

Sumber: Data dioleh, 2017

Hasil cronbachs alpha pada Tabel 6. menunjukkan nilai Partisipasi

Masyarakat sebesar 0,924, Kebijakan Pemerintah sebesar 0,955, Keberlanjutan Pariwisata sebesar 0,932, dan Kesejahteraam Masyarakat sebesar 0,925 yang artinya seluruh variabel reliabel.

4) Uji discriminant validity

Terdapat beberapa cara pengujian validitas suatu indikator, yaitu melalui uji perbandingan AVE dengan korelasi (Fornell-Larcker Criterion), uji melalui muatan silang (Cross Loadings), dan Heterotrait-Monotrait Ratio (HTMT).

Uji Fornell dan Larcker yang ditampilkan pada Tabel 7 menunjukkan hasil bahwa variabel Partisipasi Masyarakat (X1), Kebijakan Pemerintah (X2), 
Keberlanjutan Pariwisata (Y1) dan Kesejahteraan Masyarakat (Y2) dinyatakan valid karena nilai AVE konstruk lebih besar daripada varians dengan konstruk lain. Tabel 7 menggambarkan hasil uji Fornell-Larcker Criterion:

Tabel 7

Hasil uji Fornell-Larcker Criterion

\begin{tabular}{lcccc}
\hline \multicolumn{1}{c}{ Variabel } & Y1 & X2 & Y2 & X1 \\
\hline Keberlanjutan Pariwisata (Y1) & 0.932 & & & \\
Kebijakan Pemerintah (X2) & 0.762 & 0.912 & & \\
Kesejahteraan Masyarakat (Y2) & 0.929 & 0.798 & 0.922 & \\
Partisipasi Masyarakat (X1) & 0.793 & 0.678 & 0.840 & 0.932 \\
\hline Sumber: Data diolah, 2017 & & & &
\end{tabular}

Uji discriminant validity lain yangdigunakan yaitu nilai korelasi cross loading indikator lebih besar dari nilai korelasi variabel laten yang lainnya.

Tabel 8

Nilai Korelasi Cross Loading

\begin{tabular}{lccccc}
\hline & X1 & X2 & Y1 & Y2 & Keterangan \\
\hline X1.1 & $\mathbf{0 . 9 4 5}$ & 0.663 & 0.779 & 0.806 & Valid \\
X1.2 & $\mathbf{0 . 8 8 6}$ & 0.587 & 0.642 & 0.740 & Valid \\
X1.3 & $\mathbf{0 . 9 6 3}$ & 0.642 & 0.785 & 0.800 & Valid \\
X2.1 & 0.604 & $\mathbf{0 . 9 1 0}$ & 0.683 & 0.724 & Valid \\
X2.2 & 0.642 & $\mathbf{0 . 9 3 2}$ & 0.717 & 0.744 & Valid \\
X2.3 & 0.565 & $\mathbf{0 . 9 0 9}$ & 0.627 & 0.680 & Valid \\
X2.4 & 0.654 & $\mathbf{0 . 8 9 5}$ & 0.739 & 0.754 & Valid \\
Y1.1 & 0.683 & 0.670 & $\mathbf{0 . 9 0 3}$ & 0.813 & Valid \\
Y1.2 & 0.754 & 0.738 & $\mathbf{0 . 9 4 9}$ & 0.885 & Valid \\
Y1.3 & 0.778 & 0.720 & $\mathbf{0 . 9 9 4}$ & 0.896 & Valid \\
Y2.1 & 0.731 & 0.713 & 0.834 & $\mathbf{0 . 8 9 9}$ & Valid \\
Y2.2 & 0.825 & 0.769 & 0.909 & $\mathbf{0 . 9 6 1}$ & Valid \\
Y2.3 & 0.803 & 0.753 & 0.889 & $\mathbf{0 . 9 5 3}$ & Valid \\
Y2.4 & 0.799 & 0.756 & 0.889 & $\mathbf{0 . 9 4 6}$ & Valid \\
Y2.5 & 0.705 & 0.682 & 0.746 & $\mathbf{0 . 8 4 5}$ & Valid \\
\hline Sumber: Data
\end{tabular}

Sumber: Data diolah, 2017

Berdasarkan Tabel 8 uji discriminant validity menunjukkan indikator Partisipasi Masyarakat, Kebijakan Pemerintah, Keberlanjutan Pariwisata dan Kesejahteraan Masyarakat memiliki nilai lebih besar dibandingkan nilai korelasi 
Ni Kadek Ayu Indrayani, dan N. Djinar Setiawina. Pengaruh Partisipasi Masyarakat..........

cross loading variabel laten lainnya. Cross loadingPartisipasi Masyarakat (X1) dengan indikator $\mathrm{X} 1.1, \mathrm{X} 1.2$, dan $\mathrm{X} 1.3$ memiliki nilai pengaruh ke variabel latennya sebesar 0,$945 ; 0,886$; dan 0,963 lebih besar dari nilai pengaruh indikator kompensasi ke variabel laten lainnya. Nilai uji cross loading indikator Kebijakan Pemerintah juga memiliki nilai yang lebih tinggi dibandingkan dengan nilai pengaruh indikator ke variebel laten lainnya. Sama halnya dengan Keberlanjutan Pariwisata dan Kesejahteraan Masyarakat yang memiliki nilai cross loading indikatornya lebih tinggi dibandingkan dengan pengaruh indikatornya ke variebel laten lainnya. Sehingga dengan demikian, dapat disimpulkan bahwa rata-rata indikator dinyatakan valid.

Cara lain yangdapat dilakukan untuk untuk mendapatkan convergent validity adalah berdasarkan the heterotrait-monotriat ratio of correlations (HTMT) sebagaimana dikeukakan oleh Henseler, Ringle, dan Sarstedt dalam Sudjana Budhi (2016), yang menyatakan bahwa nilai HTMT sebarannya adalah lebih kecil dari 0.85 .

Tabel 9

Hasil uji the heterotrait-monotriat ratio of correlations (HTMT)

\begin{tabular}{lllll}
\hline & Y1 & X2 & Y2 & X1 \\
\hline Keberlanjutan Pariwisata (Y1) & & & & \\
Kebijakan Pemerintah (X2) & $\mathbf{0 . 8 1 6}$ & & & \\
Kesejahteraan Masyarakat (Y2) & 0.985 & $\mathbf{0 . 8 4 3}$ & & \\
Partisipasi Masyarakat (X1) & 0.853 & $\mathbf{0 . 7 2 7}$ & 0.893 & \\
\hline Sumber: Data diolah, 2017 & & & &
\end{tabular}

Dari tabel 9 terdapat tiga variabel yang memiliki nilai di atas 0,850 dan terdapat pula tiga variabel yang memiliki nilai dibawah 0,850 sehingga secara 
keseluruhan instrumen penelitian yang dipakai untuk mengukur masing - masing variabel yaitu dikatakan netral.

5) Uji Average Variance Extracted (AVE)

Nilai AVE dinyatakan valid jika nilai AVE >0,50. Nilai AVE dapat dilihat pada Tabel 10

Tabel 10.

Hasil uji Average Variance Extracted (AVE)

\begin{tabular}{lcc}
\hline \multicolumn{1}{c}{ Variabel } & AVE & Keterangan \\
\hline Partisipasi Masyarakat (X1) & 0,868 & Valid \\
Kebijakan Pemerintah (X2) & 0,849 & Valid \\
Keberlanjutan Pariwisata (Y1) & 0,831 & Valid \\
Kesejahteraan Masyarakat (Y2) & 0,869 & Valid \\
\hline
\end{tabular}

Sumber: Data diolah, 2017

Berdasarkan hasil uji AVE diperoleh hasil seluruh variabel dalam model dikatakan valid. Secara berurutan dari Partisipasi Masyarakat (X1), Kebijakan Pemerintah (X2), Keberlanjutan Pariwisata (Y1), dan Kesejahteraan Masyarakat (Y2) mempunyai nilai AVE sebesar 0,$868 ; 0,849 ; 0,831$; dan 0,869 rata-rata lebih besar dari 0,50.

\section{Hasil Uji PLS Inner Model}

1) Koefisien determinasi $R$-square $\left(R^{2}\right)$

Pengaruh substantive antara variabel laten independen tertentu terhadap variabel laten dependen lainnyadapat dilihat dari nilai $R$-square-nya. Hasil koefisien determinasi $\mathrm{R}^{2}$ ditampilakan pada Tabel 11.

Tabel 11

\begin{tabular}{lc}
\multicolumn{2}{c}{ Koefisien Determinasi $\mathbf{R}^{\mathbf{2}}$} \\
\hline \multicolumn{1}{c}{ Variabel } & $\mathbf{R}^{\mathbf{2}}$ \\
\hline Keberlanjutan Pariwisata (Y1) & 0,722 \\
Kesejahteraan Masyarakat (Y2) & 0,862 \\
\hline
\end{tabular}


Ni Kadek Ayu Indrayani, dan N. Djinar Setiawina. Pengaruh Partisipasi Masyarakat..........

Sumber: Data dioleh, 2017

Koefisien determinasi $\mathrm{R}^{2}$ sebesar 0,722 menunjukkan Keberlanjutan Pariwisata (Y1) dapat dijelaskan oleh Partisipasi Masyarakat (X1) dan Kebijakan Pemerintah (X2) sebesar 72,2 persen, sedangkan sisanya 27,8 persen dijelaskan oleh variabel lain yang tidak diteliti dalam model. $\mathrm{R}^{2}$ Kesejahteraan Masyarakat (Y2) sebesar 0,862 mampu dijelaskan oleh Partisipasi Masyarakat (X1), Kebijakan Pemerintah (X2) dan Keberlanjutan Pariwisata (Y1) secara bersama sebesar 86,2 persen dan sisanya sebesar 13,8 persen dipengaruhi oleh faktor lain di luar model penelitian.

2) Q-Square $\left(Q^{2}\right)$

Untuk mengukur nilai observasi dihasilkan oleh model dan estimasi parameter dapat dilihat dari hasil perhitungan $Q^{2}$.

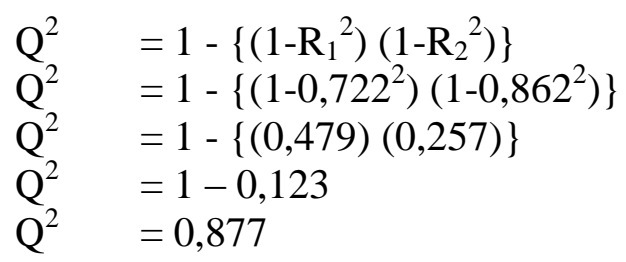

Nilai $Q$-Square yang dihasilkan sebesar 0,877 memiliki arti bahwa model penelitian mampu menjelaskan variabel dependen dan model persamaan struktural sebesar 87,7 persen dan sisanya 12,3 persen dijelaskan oleh faktor lain di luar model. 


\section{Uji Pengaruh Langsung}

Tabel 12

Pengaruh Langsung Variabel Laten

\begin{tabular}{cccccc}
\hline $\begin{array}{c}\text { Hubungan } \\
\text { Antar } \\
\text { Variebel }\end{array}$ & $\begin{array}{c}\text { Original } \\
\text { Sample }(\boldsymbol{O})\end{array}$ & $\begin{array}{c}\text { Standard } \\
\text { Deviation } \\
(\text { STDEV })\end{array}$ & $\begin{array}{c}\text { t-Statistik } \\
(|\boldsymbol{O} / \mathbf{S T D E} \boldsymbol{V}|)\end{array}$ & $\boldsymbol{p}$-Values & Keterangan \\
\hline X1->Y1 & 0,513 & 0,130 & 3,946 & 0,000 & Signifikan \\
X2->Y1 & 0,414 & 0,132 & 3,132 & 0,002 & Signifikan \\
Y1->Y2 & 0,929 & 0,021 & 44,442 & 0,000 & Signifikan \\
\hline
\end{tabular}

Sumber: Data diolah, 2017

a) Partisipasi Masyarakat Terhadap Keberlanjutan Pariwisata

Hasil analisis pada tabel 12menjelaskan bahwa Partisipasi Masyarakat berpengaruh positif dan signifikan terhadap Keberlanjutan Pariwisatadilihatnilai koefisien yaitu 0,513 , dengan nilai t-statistik yaitu 3,946, serta memiliki tingkat signifikansi 0,000. Hal ini berarti bahwa Partisipasi Masyarakat berpengaruh positif dan signifikan terhadap Keberlanjutan Pariwisata sebesar 51,3\% dan sisanya 48,7\% dipengaruhi oleh faktor lain. Artinya, semakin tinggi Partisipasi Masyarakat Nusa Penidamaka semakin baik perkembangan Keberlanjutan Pariwisata Nusa Penida. Kenyataan yang terjadi dilapangan berdasarkan hasil wawancara menyatakan bahwa, warga turut serta berpartisipasi dari tahap perencanaan hingga pengawasan. Ide atau gagasan dan informasi secara rutin disampaikan setiap minggu dalam kegiatan rapat desa atau kegiatan gotong royong. Informasi tersebut nantinya akan ditampung oleh kepala desa dan selanjutnya akan disampaikan ke pemerintah Kabupaten Klungkung melalui kunjungan Bupati Klungkung ke Nusa Penida. Partisipasi masyarakat dalam tahap pelaksanaan dilakukan dengan turut serta terlibat dalam mendukung kegiatan pariwisata seperti membuka usaha rumah makan, sebagai pemandu wisata dan 
Ni Kadek Ayu Indrayani, dan N. Djinar Setiawina. Pengaruh Partisipasi Masyarakat..........

bahkan ikut mempromosikan objek wisata kepada wisatawan. Sedangkan dalam tahap pengawasan dilakukan dengan menjaga dan mengontrol kebersihan lingkungan dan keamanan objek wisata.

Kondisi yang terjadi di Nusa Penida yaitu kepedulian masyarakat terhadap lingkungan cukup tinggi dimana sering melakukan aktifitas gotong royong seminggu sekali, meskipun masyarakat masih kerap membuang sampah sembarangan dengan alasan tidak ada TPA di beberapa desa. Kondisi lain yang terjadi adalah masyarakat sangat aktif dalam kegiatan budaya seperti kegiatan seka gong dan mempertahankan budaya daerah lainnya. Hal tersebut sangat penting mengingat budaya daerah juga menjadi daya tarik wisatawan, dan memberi kontribusi persentuhan budaya serta antar etnik serta antar bangsa.

b) Kebijakan Pemerintah Terhadap Keberlanjutan Pariwisata

Hasil analisis menunjukkan bahwa Kebijakan Pemerintah berpengaruh positif dan signifikan terhadap Keberlanjutan Pariwisata dengan nilai koefisien positif sebesar 0,414, nilai t-statistik sebesar 3,132 lebih besar dari t-tabel 1,984, serta nilai signifikansi 0,002. Hal ini berarti bahwa semakin tinggi peran pemerintah akan berpengaruh terhadap semakin tingginya peluang keberlanjutan pariwisata Nusa Penida. Hasil penelitian menunjukkan bukti empiris bahwa kebijakan pemerintah berpengaruh positif dan signifikan terhadap keberlanjutan pariwisata Nusa Penida. Berdasarkan hasil wawancara dilapangan terlihat bahwa pemerintah turut serta dalam membangun sektor pariwisata Nusa Penida. Saat ini pemerintah kabupaten Klungkung lebih memfokuskan pembangunan di Pulau Nusa Penida daripada wilayah lainnya di Kabupaten Klungkung mengingat 
pariwisata di Nuda Penida semakin berkembang. Oleh sebab itu, pemerintah kabupaten Klungkung memperbaiki infrastuktur dengan membuat jalan lingkar sepanjang 29,6 km yang akan melewati lima desa langsung baik lingkar barat dan selatan masing-masing Desa Sakti, Bunga Mekar, Batumadeg, Batukandik dan Sekartaji. Kebijakan lainnya adalah pembangunan pelabuhan segitiga emas akan dilakukan untuk menunjang pariwisata daerah yang terintegrasi di tiga wilayah, Klungkung daratan, Nusa Penida dan Lembongan.

Kebijakan pemerintah dari sisi stimulasi untuk mendukung pariwisata adalah memberikan bantuan modal usaha ekonomi pruduktif dan simpan pinjam melalui sistem peminjaman modal usaha kecil yang sudah sangat dirasakan oleh masyarakat desa dan sampai saat ini sudah dapat melayani masyarakat baik personal maupun kelompok-kelompok usaha. Selain kemudahan untuk mendapatkan modal usaha, pemerintah kabupaten Klungkung aktif melaksanakan program-program pelatihan seperti pelatihan membuat kripik singkong, dodol rumput laut dan aneka hasil olahan hasil perkebunan yang dikemas menarik sehingga dapat dijadikan oleh-oleh untuk wisatawan yang berkunjung kesana.

Dalam rangka mengembangkan pariwisata Nusa Penida, pemerintah kabupaten Klungkung mempermudah izin untuk investor yang ingin berinvestasi asalahkan tidak melanggar aturan terutama tidak merusak lingkungan. Pemerintah kabupaten Klungkung juga mengupayakan proteksi terhadap pekerja luar wilayah Nusa Penida dan lebih memberdayakan tenaga lokal dengan tujuan untuk membuka kesempatan kerja untuk masyarakat lokal Nusa Penida.

c) Keberlanjutan Pariwisata Terhadap Kesejahteraan Masyarakat 
Ni Kadek Ayu Indrayani, dan N. Djinar Setiawina. Pengaruh Partisipasi Masyarakat..........

Hasil analisismenjelaskan bahwa nilai koefesien Keberlanjutan Pariwisata Terhadap Kesejahteraan Masyarakat adalah sebesar 0,929, nilai t-statistik 44,442 lebih besar dari t-tabel 1,984dengan taraf signifikansi 0,000.ArtinyaKeberlanjutan Pariwisata berpengaruh positif dan signifikan terhadap Kesejahteraan Masyarakat sebesar $92,9 \%$ dan sisanya $7,1 \%$ dipengaruhi oleh faktor lain.Hasil wawancara dalam penelitian ini dinyatakan bahwa masyarakat Nusa Penida dari sisi aspek lingkungan memiliki kesadaran dan tanggung jawab yang tinggi untuk menjaga lingkungan dan melestarikan serta menjaga tempat wisata untuk keberlanjutan pariwisata, seperti membuat larangan membuang sampah disembarang tempat, larangan menebang pohon tanpa izin desa setempat, larangan mengekploitasi hasil laut. Sedangkan dari sisi sosial budaya, masyarakat merasa tidak terganggu terhadap budaya luar wisatawan asing. Warga masyarakat mampu beradaptasi terhadap budaya luar dengan cara memperkuat budaya dan tradisi turun temurut seperti mengajarkan anak-anak tentang tradisi sejak dini. Selain itu warga menyatakan perkembangan pariwisata dari aspek ekonomi dirasakan dapat membuka lapangan pekerjaan dan beranggapan memiliki usaha maupun bekerja di bidang pariwisata lebih menguntungkan karena dapat meningkatkan pendapatan untuk keluarga yang nantinya akan digunakan untuk biaya kesehatan, pendidikan, dan tabungan untuk keperluan masa depan. Saat ini sebagian besar masyarakat berinisiatif untuk membuka usaha yang ada kaitannya dengan pariwisata, misalnya usaha kuliner, sewa kendaraan, serta menjual produk oleh-oleh khas Nusa Penida seperti krupuk rumput laut, dodol rumput laut dan kripik singkong. 
Selain itu dengan berkembangnya daerah wisata masyarakat merasa memperoleh kemudahan akses kesehatan.

\section{Uji Pengaruh Tidak Langsung}

Hasil uji pengaruh tidak langsung variabel laten dapat dilihat pada Tabel 13 sebagai berikut:

Tabel 13

Pengaruh Tidak Langsung Variabel Laten

\begin{tabular}{cccccc}
\hline $\begin{array}{c}\text { Hubungan } \\
\text { Antar } \\
\text { Variabel }\end{array}$ & $\begin{array}{c}\text { Original } \\
\text { Sample } \\
(\boldsymbol{O})\end{array}$ & $\begin{array}{c}\text { Standard } \\
\text { Deviation } \\
(\text { STDEV })\end{array}$ & $\begin{array}{c}\boldsymbol{t} \text {-Statistik } \\
(\mid \boldsymbol{O} / \text { STDEV })\end{array}$ & $\boldsymbol{p}$-Values & Keterangan \\
\hline $\begin{array}{c}\text { X1->Y2 } \\
\text { Melalui Y1 }\end{array}$ & 0,476 & 0,121 & 3,936 & 0,000 & Signifikan \\
$\begin{array}{c}\text { X2->Y2 } \\
\text { Melalui Y1 }\end{array}$ & 0,384 & 0,125 & 3,071 & 0,002 & Signifikan
\end{tabular}

Sumber: Data diolah, 2017

a) Pengaruh Tidak Langsung Partisipasi Masyarakat Terhadap Kesejahteraan Masyarakat

Diperoleh hasil koefisiensebesar 0,476 dengan t-statistik 3,936 dan pvalues 0,000 yang artinya adalah Partisipasi Masyarakat mempunyai pengaruh tidak langsung terhadap Kesejahteraan Masyarakat melalui Keberlanjutan Pariwisata Nusa Penida. Bentuk partisipasi masyarakat Nusa Penida dapat disimpulkan seperti adanya kemauan dari responden yang secara keseluruhan ikut serta atau berpartisipasi dalam pelaksanaan pengembangan kawasan pariwisata yang dibuktikan dengan kesehariaannya aktif dalam kegiatan rapat untuk memberikan masukan terkait dengan pariwisata dan terlibat langsung dalam kegiatan pariwisataPeran aktif masyarakat tersebut akan mampu mempertahankan aspek lingkungan dengan menjaga kelestarian objek wisata, aspek sosial budaya dengan mempertahankan budaya asli daerah yang diminati wisatawan, serta aspek 
Ni Kadek Ayu Indrayani, dan N. Djinar Setiawina. Pengaruh Partisipasi Masyarakat..........

ekonomi yang dapat membuka lapangan pekerjaan. Warga masyarakat Nusa Penida menyatakan keberlanjutan pariwisata dirasakan dapat membuka lapangan pekerjaan dan dapat meningkatkan pendapatan untuk keluarga. Warga merasa sejak pariwisata berkembang, akses kesehatan menjadi lebih mudah, lebih fokus terhadap pendidikan anak-anak dan dapat memiliki simpanan untuk hari esok.

b) Pengaruh Tidak Langsung Kebijakan Pemerintah Terhadap Kesejahteraan Masyarakat

Terdapat pengaruh tidak langsung Kebijakan Pemerintah Terhadap Kesejahteraan Masyarakat melalui Keberlanjutan Pariwisata yang ditunjukkan dari nilai koefisien sebesar 0,384 dengan t-statistik 3,071 dan p-values 0,002. Hasil penelitian di Nusa Penida menunjukkan terdapat pengaruh tidak langsung kebijakan pemerintah terhadap kesejahteraan masyarakat melalui keberlanjutan pariwisata Nusa Penida, dimana kebijakan pemerintah Kabupaten Klungkung terutama dari pengembangan infrastruktur dapat mendukung keberlanjutan pariwisata dimana akses ke objek wisata menjadi lebih mudah sehingga kualitas lingkungan dan objek wisata tetap terjaga karena terkadang wisatawan sembarang mencari akses ke objek wisata melewati kebun penduduk atau pemukiman penduduk sehingga mencemari lingkungan. Pemerintah kabupaten klungkung memfokuskan pembangunan jalan dimakasudkan untuk meningkatkan perekonomian masyarakat Nusa Penida.

Dengan adanya dukungan pemerintah tersebut pariwisata Nusa Penida diyakini akan terus berlanjut karena masyarakat merasa terbantu dan menjadi lebih memiliki kesadaran tentang tanggung jawab menjaga lingkungan dan 
masyarakat melestarikan budayanya, dan pengembangkan potensi wisata sebagai daya jual. Sehingga, perkembangan pariwisata dirasakan dapat membuka lapangan pekerjaan yang akan berdampak tehadap kesejahteraan masyarakat Nusa Penida dari sisi pendapatan, kesehatan, pendidikan, kehidupan sosial hingga persiapan untuk masa mendatang.

\section{SIMPULAN DAN SARAN}

Berdasarkan hasil analisis data dan pembahasan maka dapat disimpulkan sebagai berikut: 1) Partisipasi masyarakat dan kebijakan pemerintah berpengaruh positif dan signifikan terhadap keberlanjutan pariwisata Nusa Penida. 2) Keberlanjutan pariwisata berpengaruh positif dan signifikan terhadap kesejahteraan masyarakat Nusa Penida. 3) Partisipasi masyarakat dan kebijakan pemerintah memiliki hubungan yang positif dan signifikan terhadap kesejahteraan masyarakat melalui keberlanjutan pariwisata Nusa Penida

Menyikapi hasil penelitian yang telah diuraikan maka saran penelitian ini adalah sebagai berikut: 1) Diperlukannya upaya peningkatan kualitas sumber daya manusia dengan melakasanakan pelatihan secara berkala bagi masyarakat. 2) Meningkatkan kualitas atraksi dan fasilitas pada obyek wisata agar wisatawan merasa nyaman. 3) Pemerintah Kabupaten Klungkung dapat membatu mempromosikanobyek wisata seperti melalui even budaya dan memperkenalkan ciri khas daerah melalui cenderamata/souvenir khas daerah.4) Pemerintah Kabupaten Klungkung dan masyarakat Nusa Penida dapat menjalin kerja sama dengan agen perjalanan/ travel untuk mengembangkan obyek melalui paket-paket wisata. 
Ni Kadek Ayu Indrayani, dan N. Djinar Setiawina. Pengaruh Partisipasi Masyarakat..........

\section{REFERENSI}

Albert, Michael and Robin Hahnel. 1999. Marxism and Socialist Theory: Socialism in Theory and Practice. https://books.google.co.id/.Diakses pada 26 Maret 2017.

Aleksandra Vujko and Tamara Gajić.2014. The Government Policy Impact On Economic Development Of Tourism.Economics Of Agriculture Journal. Ep 2014 (61) 3

Aref F, Gill SS, Farshid A 2010. Tourism Development In Local Communities: As A Community Development Approach. Journal of American Science, 6: $155-161$

Arun Agrawal and Clark C. Gibson.1999.Enchantment And Disenchantment: The Role Of Community In Natural Resource Conservation.World DevelopmentJournal. Vol. 27, No. 4, pp. 629-649, 1999

Bill Bramwell.2011.Governance, The State And Sustainable Tourism: A Political Economy Approach.Journal Of Sustainable Tourism, vol. 19(4/5), pp. 459-477.

Darsana, Wayan.2011.Strategi Pngembangan Daya Tarik Wisata Kawasan Barat Pulau Nusa Penida Kabupaten Klungkung.Tesis.Kajian Pariwisata Universitas Udayana

Donny Juliandri Prihadi.2015. Keberadaan Ikan Kodok (Antennarius Maculates, Desjardins 1840) di Pulau Nusa Penida Provisni Bali. Jurnal Akuatika. Vol.VI No.2 September 2015 (187-197)

Ghozali, Imam. 2012. Aplikasi Analisis Multivariate dengan Program IBM SPSS 20. Semarang:UNDIP

Hair, J.F., et al.2010. Multivariate data analysis. (7th edition). New Jersey : Pearson Education Inc.

Hall, Colin Michael. 2000. Tourism Planning: policies, processes and Relationship. England: Pearson Education. http://onlinelibrary.wiley.com.Diakses pada 28 Maret 2017

Isma Rosyida dan Fredian Tonny Nasdian. 2011.Partisipasi Masyarakat Dan Stakeholder dalam Penyelenggaraan Program Corporate Sosial Responsibility (CSR) dan Dampaknya Terhadap Komunitas Perdesaan. Jurnal Transdisiplin Sosiologi, Komunikasi, Dan Ekologi Manusia. Issn : 1978-4333, Vol. 05, No. 01. April 2011, hlm. 51-70 
Isye Susana Nurhasanah, Nava Neilulfar Alvi1 dan Citra Persada.2017. Perwujudan Pariwisata Berkelanjutan Melalui Pemberdayaan Masyarakat Lokal di Pulau Pahawang, Pesawaran, Provinsi Lampung. p issn 08527458- e issn 2356-0266. Vol 19 No 2, Mei 2017, 117-128

Jamal T, Stronza.2009. Collaboration Theory And Tourism Practice In Protected Areas: Stakeholders, Structuring And Sustainability. Journal of SustainableTourism. Vol 17: 169-189

James Elliott.1997. Tourism: Politics And Public Sektor Management.International Journal Of Tourism Research.Vol 3, issue 2, pages 176-177, march/april 2001

Joanne Connell, Stephen J. Page and Tim Bentley.2009. Towards Sustainable Tourism Planning In New Zealand: Monitoring Lokal Government Planning Under The Resource Management Act. Tourism Management.Vol 30 (2009) pp 867-877

Joko Tri Haryanto.2014. Model Pengembangan Ekowisata Dalam Mendukung Kemandirian Ekonomi Daerah Studi Kasus Provinsi DIY. Kawistara.Vol.4, No.3,22 Desember 2014.

Ma'rifatul Kholifah, 2015.Pengetahuan, Sikap Dan Partisipasi Masyarakat Lokal Dalam Upaya Pengembangan Pariwisata Di Kabupaten Banyuwangi.Doc Slide Universitas Negeri Surabaya.http://dokumen.tips. Diakses pada 10 Maret 2017.

Michael Fagence, 2001. Cultural Tourism: Strategic Interventions To Sustain A Minority Culture. The Journal Of Tourism Studies Vol. 12, No. 2, DEC. 2001

Michael Muganda, Agnes Sirima And Peter Marwa Ezra.2013. The Role of Lokal Communities In Tourism Development: Grassroots Perspectives From Tanzania. J Hum Ecol. Vol 41 No1: 53-66 (2013)

Nasikun. 1997. Model Pariwisata Pedesaan: Pemodelan Pariwisata Pedesaan Untuk Pembangunan Pedesaan Yang Berkelanjutan. Dalam ProsidingPelatihan dan Lokakarya Perencanaan Pariwisata Berkelanjutan. Bandung:Institut Teknologi Bandung.

Purbadharmaja, Ida Bagus, Made Sukarsa, Ida Gusti BagusIndrajaya, Wayan Yogiswara, dan Putu DesyApriliani.2014. Profil Penduduk Miskin Di Desa - Desa Pesisir Nusa Penida, Kabupaten Klungkung.Jurnal Buletin Studi Ekonomi. Vol. 19, No. 1

Sudjana Budhi.2016. Panduan Pelatihan SEM dan Path SEM PLS Bahan 1. Pusat Analisis Data Ekonomi Bisnis Fakultas Ekonomi Universitas Udayana 
Ni Kadek Ayu Indrayani, dan N. Djinar Setiawina. Pengaruh Partisipasi Masyarakat..........

Theobald, W .2005.Global Tourism. Third Edition. Elsevie. https://books.google.co.id/.Diakses pada 26 Maret 2017.

Timothy DJ.1999. Participatory Planning: A View of Tourism In Indonesia. Annals of Tourism Research.Vol 26: 371-391.

Tosun C.2006. Expected Nature of Community Participation In Tourism Development.Tourism Management Journal.Vol 27: 493-504

Werdika Damayanti, Ida Ayu Kade, I Nengah Wijaya, I Nyoman Kanca.2015.Strategi Pengembangan Pulau Nusa Penida Sebagai Kawasan Pariwisata yang Berkelanjutan.Soshum Jurnal Sosial Dan Humaniora. Vol. 5, No.2, juli 2015

Yi Wang dan Bill.2012.Heritage Protection And Tourism Development Priorities In Hangzhou, China: A Political Economy And Governance Perspective.Tourism Management Journal, Vol. 33, pp. 988-998.

Yunia Nursita Sari dan Petrus N. Indrajati.2015. Prinsip Pengembangan Kampung Wisata Budaya Baluwarti Yang Berkelanjutan.Jurnal Perencanan Wilayah Dan Kota A Sappk.Vol 4 No 2 